\title{
Which Foreign Language Should Be Taught in the Albanian Education System?
}

\author{
Eva Papamihali \\ eva.papamihali@gmail.com, \\ PhD. Cand. Faculty of Human Sciences, \\ Aleksander Xhuvani University; Elbasan
}

Abstract

\begin{abstract}
Until the 60s in the XX century, in Europe, foreign languages were a privilege aimed just for the rich, the educated and some other people who had specific crafts. Today in Europe and Albania, the foreign languages are part of the daily activities of lots of people. These languages enable getting and using a variety of information and nowadays this process is becoming easier and easier thanks to the increasing number of people who know one or even more foreign languages. Everybody knows and expresses the fact that foreign languages are a "must". The question which arises immediately after that is which of these languages we should learn. While attempting to answer the first one, there arises the second question, the third one and so on. What is communication like today? What will it be like in the future? Starting from the moment we think and dream about a future, there are still concrete opportunities to be analyzed so as to how we can get there. Along this article, we will reflect on communication today and we will describe the challenges that teaching foreign languages in Albanian schools should face. According to the statistics of the Eurobarometer in Europe (Special Eurobarometer 243. 2006) the biggest part of Europeans $(65 \%)$ first get in touch with the foreign languages at school. It is school which enables the longest contact with the foreign languages. This fact makes school the most important and the most critical element to be studied compared to the supportive policies of multilingualism in communication.
\end{abstract}

Keywords: languages, education, multilingualism, communication

\section{Foreign languages in XXI century}

Let's see how communication in represented nowadays.

By analyzing the last decades we notice a rapid growth of contacts with foreign information, of communication and interactivity which surpasses the national boundaries, of linguistics and cultures. Thanks to the media, the information and general technology means development, everybody, by making use of three mouse clicks, can get data from every civilization and every language in the world. We can have a low cost global communication by means of either the telephone, electronic mail or virtual communication. Travelling beyond national boundaries has become quicker, more economical and more ordinary. Spending a weekend in a city which is a thousand kilometers far away seems as normal as a business trip for a couple of days in another continent. More and more private businesses are becoming active internationally. They make business deals with foreign countries, buy and sell, exchange services with lots of countries which speak different languages. Employers have to communicate with foreign customers, to briefly travel to foreign countries with other cultural development and where other languages have been developed. In the meantime, if we analyzed the scientific development, the scientific editions are globally widespread. Nowadays scientists and researchers put up virtual working groups or they work abroad, in international working groups. Eventually the students are the ones who are getting ready for this world, let's call it modern, and we have recently noticed that many of them have increased their requests and aims to attend courses, part or full time studies abroad, even without going to these places, but directly through computers.

This is what we often call 'globalism'. This world process is intensively developing in Europe because of the economic and political unification processes.

\subsection{Let's get back to school}

The subject of teaching foreign languages belongs to the educational system of every country and this system is responsible for the quality and maintenance of the whole lesson process (Atlan, J. 2000). Regarding this matter, the Albanian system should raise its questions about updating and the results of the actual methods, but their analyses isn't 
the aim of this speech. We aim to directly treat the contradiction which the Albanian teaching system faces nowadays, in accordance with the public or social request to follow the thesis 'only English' and the approved policy by the Albanian state which supports 'multilingualism'. To achieve this we should analyze the linguistic environment in our country, the European environment as well as the global one. This requires giving a critical glance to the environment where we live today, where we want to live tomorrow and the chances we have to achieve our aims. The facts reflect that it is this environment which conditions the practicalities of teaching foreign languages. Today we are facing a dilemma: which foreign languages should we teach our pupils, students or children in Albania. Should we follow a neighbor policy or country economic relationship, thus encouraging the teaching of Italian, Greek, Turkish, or should we act in accordance with the orientations imposed by a European or global linguistic policy and which are the contradictions it brings along?

\subsection{LET'S STOP ON WHAT WE CALL 'THE LANGUAGES' DYNAMICS'}

It has been scientifically proved that when a group of people who have different native languages meet for an $\mathrm{X}$ reason, and they are asked to communicate with one another, there is always a language which tends to collect more communicators and naturally there comes an immediate tendency to preserve that language as a means of communication within the group. If this language preserves the same status in different and numerous groups, then we will have even more people who do not practice this language, becoming more aware to use it. Thus we will have a language with a privileged status getting even more reinforced (Brodin, E. 2007).

Based on this notification which greatly supports the pragmatic and theoretical viewpoints, we conclude that this is what has happened to the English language nowadays. This is the reason why we fully support the theory of English for international communication. With all the official declarations of the European Community in favor of multilingualism, the English language continues to stand on top of the languages pyramid, thus being more easily comprehended. Regarding the other languages' dynamics, all countries, including here even Albania, try to orientate this movement by following some criteria which have been set without making any specific study, that's why I would call it sensing rather than criteria. A really clear indicator of this dynamics is the fact that just a few years ago, in Albanian cities, the schools were separated into 50 $\%$ English and $50 \%$ French, whereas today this percentage has varied and the parents choose their children's schools in accordance to the foreign language they teach. A deep avoidance of the French language is noticed and there is a great tendency to substitute it with the English and German languages. We can mention here an example from a secondary school in Elbasan "Sul Harri" where the pupils of the fifth class in 2012 - 2013 studied French as a second language and then in the sixth class in 2013 - 2014 they stopped learning French in order to learn German. Should we accept the fatality of this 'languages dynamics' making it evident that the English language in itself isn't the real matter, but it is the general linguistic hegemony without considering on which languages benefit it is used. If we analyze this question, we should consider all the elements which make up this matter because we can't limit ourselves just on the communication matter and the symbolic aspects it includes, though they are an important part of reality. I think that first of all we should measure the considerable economic size which the linguistic hegemony brings to the countries or places which have a native language set in a hegemonic position. By concretely analyzing the hegemony of the English Language, we can mention some of its consequences.

- Firstly we have the creation of huge monopolies in the translation, interpretation, English texts publishing, English teaching and the production of pedagogical materials to make that possible.

- Secondly, the English gain a great saving of time and money in international communication whereas the others have to attempt, to spend time and money to learn this language, to communicate through it and to profit by the messages it's transmitted.

- The English save time and money even for the fact that they don't have to learn other foreign languages.

- The English have the opportunity to invest what they didn't spend on learning foreign languages in other areas.

- $\quad$ The English have a dominant position in every situation of negotiation, they stand higher than the competitors and profit from the English language to choose the conflicts in their favor (Demaizière, F. \& J.-P. Narcy-Combes. 2005).

- The existence of these consequences is often surpassed and up to now we have no detailed studies though the number of Albanian children registered in English courses increases and the methods of teaching English advance, are updated and sold at an incredible speed.

I am convinced that if something like this happened in all other areas of public policies, it would soon be considered as unacceptable. If one day, I hope soon, Albania becomes part of the European community, it will stand in the position of the 
loser as most of the other countries which already have this status.

\subsection{WHICH ARE THE PROBABLE LINGUISTIC POLICIES?}

Are there any economical linguistic policies? If such policies do exist, what are the measures to be undertaken in order to apply them? Let's analyze two possible scenarios.

The first scenario is the one of the multilingualism. We can define multilingualism as the linguistic regime organized in such a way that it enables inter - European communication in many languages (Narcy-Combes, J.-P. 2006). Obviously this scenario ends the hegemony of the English language.

The second scenario, theoretically, could be the one of finding or developing an artificial language belonging to no one, just like Esperanto, which could be adjusted as an international communication language for everyone.

From an economic viewpoint, this second scenario would obviously be the best choice for Albania, as well as for every non - English country. This imaginary language would avoid the consequences we mentioned above, thus making everyone attempt to translate and interpret from native language to the so called international one. This process would be far more economic as it would be spent for the learning of a unique language which would be easier than English or any other languages to acquire.

If we give a brief glance to the scenario of multilingualism, it won't result more economic as we suppose that the learning of every language costs more or less as the learning of English, but if we have to see the glass as half full rather than half empty, we can say that multilingualism gives to every language an equal weight to the demographic weight of the community who speaks it.

So though briefly, we saw that there are other alternatives apart from the thesis 'everything English'.

When we talk about linguistics it is the same as when we talk about ecology because the decisions made in these areas are effective only when they are taken and undertaken in all countries (Toma, A. 2007). If a country legalized and applied multilingualism while the others it cooperates with would all practice the same international language, we would face the fact that this country would see a great deal of attempts and money thrown away because of what we called 'languages' dynamics". Fortunately, the European Union and the states which are its members have acquired the position which is the promotion of the language variety which should then be followed in the policy of language education. Apart from mobility, respective communication and economic development, Europe tends to preserve the European cultural heritage where language variety is an essential component. This is a matter which does not only treat the development and preservation of languages, but it enables the European citizens to develop their language skills. Learning a language should be seen as the development of the specific language skill of each individual and this skill should be developed not just for practical or professional reasons, but even as an education to respect the others' languages and the variety of languages. These arguments fully support the policy for the language education which encourages the increase of abilities to learn some foreign languages for all the citizens throughout their lives. This is the only way for Europeans to become multilingual and intercultural citizens, capable of communicating with other Europeans about all aspects of their lives.

Learning some languages in Europe, obviously does not decrease the economic costs, but adopting a similar policy avoids unequal privileges among countries with great languages. To be concrete, this policy of teaching foreign languages at schools would consist in the obligatory learning of two or three foreign languages among which English could not stand systematically. In this case every country should give priority to the learning of languages which belong to its main partners, which could be reinforced with bilateral agreements.

- By means of gifts in books and didactic materials, financing different activities mainly through the French Alliance, the French government tries to preserve the decreasing reputation of the French language and also to protect the status which French actually has at schools.

- If we read the journey of the German language described in the article of May, 5-th, 2014 read by the head of the German Department at the University of Tirana Prof. Dr. Brikena Kadzadej, we notice that German is present in many schools. 
- In December 2012 Albania and Italy signed a cooperation agreement in the framework of the second phase of the 'lliria' program. The agreement aimed teaching Italian as a first foreign language at elementary schools and high schools in all the Albanian territory.

There have been similar agreements in Albania and I hope there will be even in the future, but when we see the attempts that many countries make to spread their languages in Albania (I should have mentioned here even the attempts which are made to teach Turkish and Greek in schools) there arises the question: does the Albanian state have a clearly specified policy in this regard? I would say no as this is verified by the fact I am going to read now.

In the first instruction, $\mathrm{nr}$ 60, and date December 26-Th 2013, for the development of the maturity exams, MAS (Ministry of Education and Science) established that: The test of foreign languages will be made in accordance with the language which is each candidate's favorite. The selection of the student for this exam will be reflected in the respective form. In item 1.3 of this guide it was stated that: "The test of the foreign language, as an obligatory exam, would be developed by the AKP (the National Agency of Exams) and the result would be implemented by the AKP (the National Agency of Exams) itself.

In the second instruction, which dates February 7-Th 2014, the Ministry of Education has reconsidered it and has changed some items of the instruction, by removing the right they had given to the graduates in the first instruction. But in this second instruction it was specified that the graduate would take an obligatory exam, the first language he/she has done at school. And apart from that, it won't be AKP (the National Agency of Exams) to make the implementation as it was defined in December, but it will be done by the respective Education Directory. Also, changes have been made even about the item which defined how the foreign language selection that the graduate prefers to take as a facultative exam would be done. In the first instruction it was stated that: The graduate has the right to select only one foreign language, which is treated as the first foreign language in the school lesson plans, no matter if it has been done at school or not.

These letters show nothing but the fact that there is uncertainty in the way of organizing multilingualism, though the European Union has brought in Albania the translated manual which explains the principles and recommendations of the European Union so as where the educational policies which urge language variety should be based. This article entitled "A guide to the development of language education in Europe", in its executive version in 2007, (Beacco, J- C. \& Byram, M. 2007 ) is the promotion of a critical reflection over the widely protected attitudes regarding the language learning and the established actual attempts which deal with the policy of language education.

\subsection{CONCLUSION}

I express my final thought that it is necessary in all this matter to reformulate clear objectives regarding the distribution of foreign languages in schools in Albania, either private or public. The objectives should consider the geopolitical situation of the country: which languages are present in the respective territory, which languages are present in its boundaries, what social and economical ambitions the country has for its future. The vision for the future should be expanded even to China, but this vision should be clear so as every eye can see the coastlines in the horizon.

\section{Bibliography.}

i.2006. Europeans and their Languages, Special Eurobarometer 243, Directorate General for Education and Culture, European Commission. [En ligne] https://open-data.europa.eu/en/data/dataset/S518_64_3_EBS243

ii.Atlan, J. 2000. « L'utilisation des stratégies d'apprentissage d'une langue dans un environnement des TICE ». [En ligne] http://alsic.u-strasbg.fr/Num5/atlan/alsic_n05-rec3.htm. DOI : 10.4000/alsic.1759

iii.Brodin, E. 2007. « Innovation, instrumentation technologique de l'apprentissage des langues : des schèmes d'action aux modèles de pratiques émergentes ». En ligne] http://alsic.u-strasbg.fr/Num09/brodin/alsic_n09-rec3.htm. DOI : 10.4000/ alsic. 2070

iv.Demaizière, F. \& J.-P. Narcy-Combes. 2005. « Méthodologie de la recherche didactique : nativisation, tâches et TIC ». Alsic Volume 8, 2005 : 45-64. Article mis en ligne en novembre 2005.http://alsic.u-strasbg.fr/v08/demaiziere/alsic_08_14rec8.htm. 
v.Narcy-Combes, J.-P. 2006. « Les TIC dans l'enseignement supérieur : pratiques et besoins des enseignants ». Les Cahiers de l'Acedle, numéro 2, 2006, "Recherches en didactique des langues », colloque Acedle, juin 2005. [En ligne] http://acedle.u-strasbg.fr/rubrique.php3 ?id_rubrique $=7$.

vi.Toma, Antoine. 2007. « Un modèle communicationnel » In Le laboratoire LAIRDIL Site du Laboratoire LAIRDIL [En ligne]. http://www.lairdil.org/htm/publi.php ?idmembre $=3$.

vii.Beacco, J- C. \& Byram, M. 2007. "Guide for the Development of Language Education Policies in Europe" Council of Europe, Strasbourg. 